Bekkema, N., Veer, A.J.E. de, Albers, G., Hertogh, C.M.P.M., Onwuteaka-Philipsen, B.D., Francke, A.L. Training needs of nurses and social workers in the end-of-life care for people with intellectual disabilities: a national survey. Nursing Education Today: 2014, 34(4), 494-500

\begin{tabular}{|l|l|}
\hline $\begin{array}{l}\text { Postprint } \\
\text { Version }\end{array}$ & 1.0 \\
\hline Journal website & http://www.nurseeducationtoday.com/article/S0260-6917(13)00269-4/abstract \\
\hline Pubmed link & $\underline{\text { http://www.ncbi.nlm.nih.gov/pubmed/23972684 }}$ \\
\hline DOI & $10.1016 / j . n e d t .2013 .07 .018$ \\
\hline
\end{tabular}

This is a NIVEL certified Post Print, more info at http://www.nivel.eu

\title{
Training needs of nurses and social workers in the end-of-life care for people with intellectual disabilities: A national survey
}

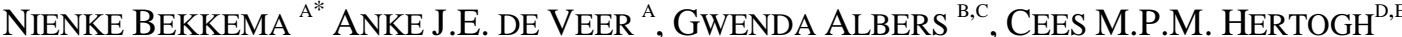
BREGJE D. ONWUTEAKA-PHILIPSEN ${ }^{\mathrm{C}, \mathrm{E}}$, ANNEKE L. FRANCKE ${ }^{\mathrm{A}, \mathrm{C}, \mathrm{E}}$

${ }^{a}$ NIVEL, Netherlands Institute of Health Services Research, P.O. Box 1568, 3500 BN Utrecht, The Netherlands

${ }^{\mathrm{b}}$ End-of-Life Care Research Group, Ghent University \& Free University of Brussels, Department of Family Medicine, Free University of Brussels, Brussels, Belgium

${ }^{c}$ Department of Public and Occupational Health, EMGO Institute for Health and Care Research, VU University Medical Center, P.O. Box 7057, 1007 MB Amsterdam, The Netherlands

${ }^{\mathrm{d}}$ Department of General Practice \& Elderly Care Medicine, EMGO Institute for Health and Care Research, VU University Medical Center, P.O. Box 7057, 1007 MB Amsterdam, The Netherlands

${ }^{\mathrm{e}}$ Expertise Center for Palliative Care Amsterdam, VU University Medical Center, Amsterdam, The Netherlands

\section{S U M M A R Y}

Background: Nurses and social workers caring for people with intellectual disabilities are increasingly confronted with clients in need of end-of-life care. Previous studies, however, suggest that professionals in intellectual disability care services lack knowledge and experience concerning end-of-life care. Moreover, the proportion of nurses within the staff of intellectual disability services has declined in recent years, while the proportion of social workers has increased, which may have consequences for the quality of end-of-life care.

Objectives: To gain insight into the quality of end-of-life care, past vocational training, training needs and expert consultation opportunities of nurses and social workers working in intellectual disability care services.

Design: Survey questionnaire study conducted in the Netherlands.

Settings: Intellectual disability care services.

Participants: The study sample was recruited from an existing nationally representative research panel of care professionals. In 2011, all 181 nurses and social workers in the research panel who worked in intellectual disability care services were sent our survey questionnaire. 
Bekkema, N., Veer, A.J.E. de, Albers, G., Hertogh, C.M.P.M., Onwuteaka-Philipsen, B.D., Francke, A.L. Training needs of nurses and social workers in the end-of-life care for people with intellectual disabilities: a national survey. Nursing Education Today: 2014, 34(4), 494-500

Methods: Postal survey addressing education, views and needs regarding endof-life care.

Results: The response was $71.8 \%$. Respondents positively evaluated the quality of end-of-life care. However, most respondents felt inadequately trained in endof-life care issues. Nurses had received more training in end-of-life care and had fewer training needs than social workers. Respondents wished for additional training, especially in supporting clients in dealing with the impending death and farewell process. Half of the respondents were unaware of the availability of external consultation facilities.

Conclusions: This study shows that although nurses and social workers positively appraise the quality of end-of life care for people with intellectual disabilities, the majority feel inadequately trained to provide good end-of-life care. As the number of people with intellectual disability in need of end-of-life care grows, organizations need to offer additional relevant training and must give information about the availability of external expert consultation for nurses and social workers.

\section{INTRODUCTION}

Professionals caring for people with intellectual disabilities (ID) are confronted with an aging population. Since health care has improved over recent decades, the life expectancy of people with ID has increased. However, the increased life expectancy is connected with growing incidences of life-limiting illnesses such as progressive cancer, chronic cardiovascular diseases, chronic lung diseases and dementia (Ellison and Rosielle, 2008; Janicki et al., 1999; Tuffrey-Wijne et al., 2007). As a result, professionals increasingly encounter people with ID who are in need of end-of-life care, a specific type of care requesting specific expertise and training. End-of-life care focuses heavily on the quality of life by relieving pain and other distressing symptoms, incorporating the holistic needs of people, as reflected in physical, psychological and spiritual support.

Professionals need a variety of knowledge and skills in order to provide comprehensive, multidisciplinary end-of-life care to the person and their family (de Vlieger et al., 2004). End-of-life care for people with ID can be especially challenging due to pre-existing intellectual disabilities combined with physical impairments resulting from a life-limiting illness. Professionals encounter difficulties, for example, in communicating about end-of-life issues with their clients (Bekkema et al., 2013; Stein, 2008; Tuffrey-Wijne et al., 2010). Furthermore, the identification and management of pain and other symptoms can be hard at the end of life, as signals that express pain or other distress can be very small and hard to recognize in people with ID (Bekkema et al., 2011; Ryan et al., 2010). As the work of professionals caring for people with ID has a strong focus on activating people rather than on 'caring' and symptom relief, end-of-life care may not be a matter of course (Kirkendall et al., 2012; McCallion et al., 2012; Mccarron et al., 2010). Previous studies suggest that professionals working in ID care services may lack knowledge and skills concerning end-of-life care. Ng and Li (2003) found that in the 
Bekkema, N., Veer, A.J.E. de, Albers, G., Hertogh, C.M.P.M., Onwuteaka-Philipsen, B.D., Francke, A.L. Training needs of nurses and social workers in the end-of-life care for people with intellectual disabilities: a national survey. Nursing Education Today: 2014, 34(4), 494-500

UK, $50 \%$ of the professionals who care for incurably ill people with ID were unable to identify signs and symptoms of the illness. Ryan et al. $(2010,2011)$ found that Irish professionals caring for people with ID often lacked confidence and training in end-of-life care, and that providing end-of-life care therefore led to considerable stress. Lack of training in end-of-life care was also rated as an obstacle by $72 \%$ of the directors of ID care services in the USA (Botsford, 2004).

Likewise, a recent study in Australian ID community group homes revealed that less than one third of the professionals concerned received any training in end of-life care (Wiese et al., 2012a).

Also, research performed in the Netherlands among managers and physicians in ID care services suggested that professionals often have insufficient expertise with endof-life care (Bekkema et al., 2011). In the Netherlands, professionals caring for people with ID have varying backgrounds, but the large majority are social workers, followed by nurses (RNs) and certified nursing assistants (CNAs) (Van derWindt et al., 2009). The de-institutionalization of the care for people with ID that started in the 1970s and the disappearance of specific vocational training in ID nursing in the 1990s led to a decrease in the number of nurses working in this field in the Netherlands that is still ongoing (AVVV, 2004; CBS Statistics Netherlands, 2012). This necessitated a redefinition of the position of nurses working in ID care services in relation to other disciplines such as social workers; a development that also took place in other countries such as the UK and Ireland (Sheerin and McConkey, 2008; Sweeney and Mitchell, 2009). A survey performed in 2002 in the Netherlands revealed that $81 \%$ of the nurses working in Dutch ID care services expressed a need for additional training in end-of-life care (De Veer et al., 2004). No social workers were involved in the 2002 survey, but it seems probable that social workers will have received less training in end-of-life issues in their vocational training programs than nurses and that therefore their training needs will be also more pronounced. Indeed, since then there has been growing attention in the Netherlands for the quality of endof- life care in ID care services, seen for example in the provision of training courses and consultation facilities on end-of-life care. In principle, these consultations facilities are available to all health-care professionals and may complement missing knowledge, especially for teams with no first-hand expertise in end-of-life care.

In order to further promote good care for incurably ill people with ID, more insight is needed into past vocational training in end-of-life care, the training needs and the consultation options of nurses and social workers. It is also important to know how nurses and social workers evaluate the quality of the end-of-life care provided by their team. Given their educational background, we expect that nurses will have received more training in at least the physical side of end-of-life care, will have fewer training needs and will be more aware of end-oflife care consultation facilities than social workers. The research questions are:

1. How do nurses and social workers in ID care services appraise the quality of end-of-life care provided by their team or department?

2. What views or needs do nurses and social workers have with regard to:

- training in end-of-life care? 
Bekkema, N., Veer, A.J.E. de, Albers, G., Hertogh, C.M.P.M., Onwuteaka-Philipsen, B.D., Francke, A.L. Training needs of nurses and social workers in the end-of-life care for people with intellectual disabilities: a national survey. Nursing Education Today: 2014, 34(4), 494-500

- facilities that enable consultation of internal and external experts related to end-of-life care?

\section{METHODS}

\section{Sample}

The study sample was recruited from an existing nationally representative research panel of care professionals in the Netherlands (De Veer and Francke, 2010; De Veer et al., 2011). This research panel consists of a group of care professionals who are prepared to fill in questionnaires on current topics in health care. In 2011, all 181 participants (RNs, CNAs or social workers) in the research panel who worked in care services for people with ID were sent our survey questionnaire.

\section{Data Collection And Survey Questionnaire}

The questionnaire contained questions on education, actual experiences and attitudes regarding end-of-life care. The questions were derived from an existing survey questionnaire which was proven to be valid and useful in earlier research (De Veer et al., 2004). Recent experience in end-of-life care was measured by asking the respondents: have you cared for a client who died from chronic illness or old age during the last two years? To measure the evaluation of the quality of end-of-life care of the team, respondents were asked: how do you appraise the quality of end-of-life care in your team or department? (The response categories were 'very good', 'good', 'moderately good', 'moderately bad', 'bad', plus 'not applicable' if end-of-life care was not provided by the team/department.) To measure past training in end-of-life care, the respondents were asked: what topics or skills related to end-of-life care were covered in your vocational training (basic and post basic)? A list of 15 different education topics was given, which are described in Table 3. Respondents could also indicate whether they were able to take a separate module addressing end-of-life care. In a separate question we asked: do you feel adequately trained to provide good end of- life care? To measure current training needs in end-of-life care, the respondents were asked: in what topics or skills related to end-of-life care would you like additional training? A list of 16 different training needs was given, which are described in Table 4. To measure consultation facilities related to end-of-life care, the respondents were asked whether experts on end-of-life care could be consulted within and outside their organization, and if this was not the case, whether they would like such consultation facilities to become available. Also, some questions on background characteristics and work-related characteristics were included.

\section{Ethical Consideration}

As this was a questionnaire-based study without any intervention, no approval by an ethics committee is required in the Netherlands.

\section{Analysis}

T-tests and Chi-square tests were used to describe background characteristics of the respondents. In order to answer research question 1 , multiple linear regression was performed to explore differences in perceived quality of end-of-life care by professional background, corrected for the influence of recent experience in end-of- 
Bekkema, N., Veer, A.J.E. de, Albers, G., Hertogh, C.M.P.M., Onwuteaka-Philipsen, B.D., Francke, A.L. Training needs of nurses and social workers in the end-of-life care for people with intellectual disabilities: a national survey. Nursing Education Today: 2014, 34(4), 494-500

life care. In order to answer research question 2,multiple logistic regression analysiswas performed to explore differences in past vocational training and training needs by professional background, corrected for the influence of recent experience in end-of-life care. Odds ratios and 95\% confidence intervals were calculated. Poisson regression was performed to explore differences in the mean number of end-of-life care topics covered in vocational training and the mean number of different training needs by professional background, corrected for the influence of recent experience in end-of-life care. Differences in the perceived availability of consultation facilities by professional background were tested using Chi-square tests.

An adjustment weight was assigned to nurses and social workers in order to calculate total group percentages that more accurately represent the population distribution of nurses and social workers working in Dutch ID care services. The tables present percentages for nursing staff and social workers separately, and weighted percentages for the total group of respondents. All analyses were performed using Stata 12.1.

\section{RESULTS}

\section{Background Of The Respondents}

130 questionnaires were completed (a response of 71.8\%). The group of nursing staff is comprised of nurses with an associate degree or Bachelor's degree $(n=87)$, and also includes a small group of certified nursing assistants $(n=6)$. The group of 37 social workers is comprised of social workers with an associate degree or Bachelor's degree. Table 1 shows that the nurses in this study are on average older and have more work experience as a qualified care professional than the social workers. One in five was involved in end-of-life care in the last two years. Only a small percentage (4\%) work in a team or department specialized in end-of-life care. The responding nurses have more experience in providing end-of-life care in the last two years (38\%) than social workers (14\%).

\section{Appraisal Of The Quality Of End-Of-Life Care}

Table 2 shows that the quality of end-of-life care is highly valued.

Almost $80 \%$ of the respondents perceived the quality of end-of-life care delivered by their team or department to be good or very good.

No relationship was found between the professional background and appraisal of end-of-life care.

\section{[TABLE 1][TABLE 2]}

\section{Past Training In End-Of-Life Care}

Table 3 shows that only $15 \%$ of the respondents felt adequately trained to provide good end-of-life care. No differences related to professional background were found. In general, most respondents (78\%) covered at least one aspect of end-of-life care in their vocational training (basic and/or post basic). However, only 6\% took a separate module on end-of-life care. Topics concerning psychosocial and spiritual care were 
Bekkema, N., Veer, A.J.E. de, Albers, G., Hertogh, C.M.P.M., Onwuteaka-Philipsen, B.D., Francke, A.L. Training needs of nurses and social workers in the end-of-life care for people with intellectual disabilities: a national survey. Nursing Education Today: 2014, 34(4), 494-500

most likely to be covered, but no end-of-life topic was covered in the vocational training of more than $42 \%$ of the respondents.

With the exception of the physical care of a deceased client, end-of-life topics related to the physical and medical care, in particular the use of instruments to measure pain or other symptoms, were barely covered in the vocational training. Nurses were more likely to receive training in the physical care of a deceased client than social workers. Within the category psychosocial and spiritual care, the topics most likely to be covered were support in dealing with the impending death and conducting 'badnews' conversations. Religious and spiritual support, and conversations about the meaning of life were less likely to be covered. Nurses were significantly more likely to be trained in the provision of support in dealing with the impending death than social workers. Within the category practical and complementary care, more nurses were trained in practical issues surrounding the dying process and the funeral than social workers. Complementary care such as massage and end-of-life care in other cultures were covered less often.

Within the category personal and team development, nurses were more likely to have been educated in cooperating with other professions in end-of-life care than social workers.

The mean number of different end-of-life care topics covered in vocational training was 2.9 (range of $0-13$ ). Nurses received training on more topics (3.8) than did social workers (2.5) (Coef: -0.3894 [ -0.632 to -0.147$]$ ).

\section{Training Needs}

Table 4 shows that almost 70\% felt a need for additional training in end-of-life care. In general, respondents were most interested in training on how to support clients in dealing with the impending death and the farewell process, knowledge about end-oflife care in other cultures, and law and regulations on euthanasia and assisted suicide. There were no significant differences between nurses and social workers regarding training needs.

Concerning physical and medical care, respondents were most likely to want to be educated in law and regulations on euthanasia and assisted suicide, palliative sedation and end-of-life decisions such as starting or foregoing treatment. Concerning psychosocial and spiritual care, respondents primarily wished to be trained in how to support a client in dealing with the impending death and the farewell process. Concerning practical and complementary care, respondents primarily wished for training in knowledge on end-of-life care in other cultures. One in five respondents wished to be trained in dealing with their own grief. The mean number of training needs was 3.3 (range of $0-13$ ). Social workers had more training needs (3.6) than nurses (2.8) (Coef: 0.275 [0.048 to 0.503]).

Perceived Availability Of Consultation Facilities And Need For Them $79 \%$ of the respondents said that internal expert consultation on end-of-life care is already available in their organization, whereas $8 \%$ expressed a need for internal consultation facilities. However, only $50 \%$ of the respondents stated that external consultation facilities are already in place, whereas $24 \%$ expressed a need for this type of consultation.

We found no differences between nurses and social workers in this regard. 
Bekkema, N., Veer, A.J.E. de, Albers, G., Hertogh, C.M.P.M., Onwuteaka-Philipsen, B.D., Francke, A.L. Training needs of nurses and social workers in the end-of-life care for people with intellectual disabilities: a national survey. Nursing Education Today: 2014, 34(4), 494-500

\section{[TABLE 3]}

\section{DISCUSSION}

Nurses and social workers working in ID care services positively evaluate the quality of end-of-life care provided by their team or within their department. Nurses are more involved in end-of-life care, received more training in end-of-life care and have fewer training needs than social workers. Although most professionals received training in at least one end-of-life care topic, many topics were not covered well in (basic and/or post basic) vocational training.

Moreover, the large majority of care professionals feel inadequately trained to provide end-of-life care. The top training priority is how to support clients in dealing with the impending death and the farewell process. Although external consultation on end-of-life care is supposed to be available to all healthcare professionals, half of the respondents said that these facilities were unavailable to them.

The positive evaluation of the quality of end-of-life care seems to contradict the finding that most respondents feel inadequately trained and have extensive training needs when it comes to end-of- life care. Since most of the respondents had not cared for a dying client in the past two years, an explanation may be that although they feel insufficiently equipped to provide end-of-life care themselves, they have a high opinion of the quality of end of- life care provided by more experienced colleagues. The positive evaluation of the quality of end-of-life care may also have been influenced by emotions, as studies suggest that care professionals often experience end-of-life care as very rewarding and honorable (Bekkema et al., 2011; Wiese et al., 2012a).

\section{Education Falls ShortWhen It Comes To End-Of-Life Care}

Only a small percentage of the respondents had taken a special course on end-of-life care, and in general end-of-life care was not covered very well in the (basic and/or post basic) vocational training they had received. The topics covered most frequently concerned support in dealing with the impending death, conducting 'bad-news' conversations, the physical care of a deceased client and practical issues surrounding the dying process and the funeral. The topic that received the least attention was the use of instruments to measure pain and other symptoms, a shortage in education which has also been found among nursing home nurses (Whittaker et al., 2006). This is alarming, since pain and symptom relief are important parts of end-of-life care (WHO, 2012). Earlier research suggests that the identification and management of pain and other symptoms can be hard in people with ID, especially at the end of their life (Bekkema et al., 2011; Ryan et al., 2010). Since almost no respondents received training in the use of assessment instruments, more awareness is needed of the complexities of assessing pain and distress in people with ID (Symons et al., 2008; Regnard et al., 2007).

Strikingly, $85 \%$ of the respondents feel inadequately trained to provide end-of-life care. This is in line with the lack of training which has been found in other countries (Ng and Li, 2003; Ryan et al., 2010, 2011; Wiese et al., 2012a). Here is a task for organizations, teachers and policy makers to investigate what can be done to increase the knowledge and expertise of current and future nursing staff and social workers. End-of-life care is still a rather infrequent type of care in people with ID, although 
Bekkema, N., Veer, A.J.E. de, Albers, G., Hertogh, C.M.P.M., Onwuteaka-Philipsen, B.D., Francke, A.L. Training needs of nurses and social workers in the end-of-life care for people with intellectual disabilities: a national survey. Nursing Education Today: 2014, 34(4), 494-500

the numbers in need of end-of-life care will expand in the years to come. Studying the knowledge of nurses in the US, Schlairet (2009) found that only nurses with continuing education in end-of-life care (and not the ones with only formal education in end-of-life care) scored better on objective knowledge/skills concerning end-oflife care. It may therefore be most effective to provide continuing education on endof-life care issues to those professionals who are most likely to be confronted with clients with end-of-life care needs, e.g., those who work with older people with ID. There is a need for education interventions to reduce the gaps in knowledge and skills. For instance, Reddall (2010) developed a palliative care resource booklet for professionals caring for people with intellectual disabilities, aimed at providing easy and accessible information on end-of-life care. Other work is being done by McLaughlin et al. (2012) who developed a multimedia educational resource about end-of-life care which stimulates partnerships between ID care services and specialist palliative care services. Also, promising results came from a recent evaluation of a training program on palliative care for staff working with people with ID: staff members' levels of preparation and confidence in their ability to provide palliative care improved due to the program (Hahn and Cadogan, 2011).

\section{[TABLE 4]}

\section{Training Priorities}

The many needs for additional training in end-of-life care illustrates a willingness among professionals to provide good end-of-life care, and is in line with the willingness found in other studies (Ryan et al., 2010, 2011; Wiese et al., 2012a). Compared to the 2002 survey (De Veer et al., 2004), the overall need for end-of-life training decreased by 10 percentage points, which may be due to the growing attention for the quality of end-of-life care and the development of supporting material in Dutch ID care services in recent years. However, training needs are still very high. Just as in 2002, the top training priority remains training in how to support clients in dealing with the impending death and the farewell process. This training priority is a reminder that communication between care professionals and people with ID remains a challenge in end-of-life care, as has also been found in other studies (Stein, 2008; Tuffrey-Wijne et al., 2007, 2010). Fortunately, promising research is currently being done in this matter (Tuffrey-Wijne, 2012; Wiese et al., 2012b), although new ways for communication in the end-of-life care for people with ID still need testing in practice.

\section{Lack Of Access To External Experts}

End-of-life care should be comprehensive and multidisciplinary.

This is reflected in our results as the majority of nurses and social workers confirmed the availability of consultation with experts on end-of-life care within the organization. This exchange of knowledge seems particularly important since professionals in ID care services have varying education backgrounds and may not feel adequately trained. Within the context of knowledge exchange, a specialized palliative care consultant may function as a key person in the transfer of internal expertise. However, half of the professionals said they cannot consult relevant experts outside their organization. This is surprising as multidisciplinary consultation 
Bekkema, N., Veer, A.J.E. de, Albers, G., Hertogh, C.M.P.M., Onwuteaka-Philipsen, B.D., Francke, A.L. Training needs of nurses and social workers in the end-of-life care for people with intellectual disabilities: a national survey. Nursing Education Today: 2014, 34(4), 494-500

teams are available in all regions in the Netherlands and can be consulted by all kinds of healthcare professionals with questions about physical, psychosocial or spiritual aspects of end-of-life care. Hence, professionals working in ID care services are often not aware of these consultation facilities. Partnerships between ID care services and specialist palliative care services may considerably improve the quality of endof-life care for people with ID. Collaborative working can increase the knowledge on end-of-life care of professionals working in ID care services and it may improve the access of people with ID to generic palliative care services. Such partnerships require overcoming differences in care approaches and skill limitations (Friedman et al., 2012; Kirkendall et al., 2012; Mccarron et al., 2010; Read and Cartlidge, 2012; Ryan et al., 2010; Tuffrey-Wijne et al., 2008).

\section{Nurses And Social Workers: Differences And Opportunities For Holistic Care}

Nurses received more training in several aspects of end-of-life care. As for the physical care of a deceased client, this may be a more natural fit with nursing curriculum than in social-work curriculum. Yet, the other topics in which nurses scored higher - support in dealing with the impending death, practical issues surrounding the dying process and the funeral, and cooperating with other professions in end-of-life care - could also fit well within social-work education. The question arises whether nurses and social workers should receive the same training in end-of-life care, and whether this is feasible. In selecting their basic vocational training, most social workers did not choose to provide physical and medical care to clients. Nevertheless, end-of-life care usually involves a lot of physical care tasks. In Dutch ID care services, nurses and social workers generally work in similar positions.

The division of tasks between the professions is not clear, but in practice nurses may be more engaged with clients who have special nursing care needs, and may therefore more readily opt to care for a client who becomes ill. This would be in line with the results of our study that nurses are more involved in end-of-life care. However, as clients get ill in all types of care services, social workers will be confronted with end-of-life care needs as well. A positive finding is that social workers are aware of their responsibility to have sufficient expertise in end-of-life care, as they expressed more training needs in terms of end-of-life care than nurses. Moreover, social workers seem to acknowledge that their task goes beyond the psychosocial part, seeing that they also wish for training in the physical and medical aspects of end-oflife care. As end-of-life care is eminently holistic, multidisciplinary teams in ID care services, composed of nurses as well as social workers, may allow for the ideal combination of psychosocial, spiritual and physical expertise.

\section{STRENGTHS AND WEAKNESSES}

An important strength of this study is that respondents were recruited from an existent large, national panel of nurses and social workers. We were therefore able to provide insights into how staff working in ID care services perceive their knowledge and skills in end-of-life care. Another strength is the relatively high response rate; this might be due to the fact that all participants in the panel are in principle committed to completing survey questionnaires regularly. 
Bekkema, N., Veer, A.J.E. de, Albers, G., Hertogh, C.M.P.M., Onwuteaka-Philipsen, B.D., Francke, A.L. Training needs of nurses and social workers in the end-of-life care for people with intellectual disabilities: a national survey. Nursing Education Today: 2014, 34(4), 494-500

However, using the existing panel also has a disadvantage in the sense that staff who are highly committed and dedicated to their profession will probably be overrepresented in our study sample. Additionally, there is a limitation in thatmost questions and statements in the current study were about perceptions. Moreover, recall of basic vocational training topics may have been a problem for older respondents. Future research should therefore focus more on their actual knowledge and skills.

\section{IMPLICATIONS}

This study raises the question of whether end-of-life care for a person with ID can best be provided within an ID care service, taking into account the lack of knowledge of the nurses and social workers.

As the number of people with ID and end-of-life care needs is expected to grow, organizations must take adequate measures in order to equip care staff with the necessary expertise to answer the end-of-life care needs of their clients. Dying in one's own home environment is the preferred option for many dying people (Escobar Pinzón et al., 2011; Higginson and Sen-Gupta, 2000), and also for many incurably ill people with ID. Organizing end-of-life care is challenging, perhaps especially since many people with ID now live in small-scale housing facilities.

If we want to promote end-of-life care in the client's own home environment, good quality end-of-life care must be guaranteed. Combining opportunities for expert consultation with continuing education on end-of-life care for those professionals who are most likely to be confronted with incurably ill clients may be most effective. Being a well-skilled professional in end-of-life care also entails reflecting on one's own expertise and engaging the support of experts from outside and inside the organization for good end-of-life care for people with ID.

Conflicts Of Interest The authors have declared no conflicts of interest.

Acknowledgments The study was funded by the Dutch Ministry of Health.

\section{REFERENCES}

AVVV, 2004. Verpleegkundige in de verstandelijk gehandicaptenzorg (Nurses in ID care services). AVVV, Utrecht.

Bekkema, N., de Veer, A.J.E., Hertogh, C.M.P.M., Francke, A.L., 2011. Palliatieve zorg voor mensenmet een verstandelijke beperking (Palliative care for people with intellectual disabilities). NIVEL, Utrecht.

Bekkema, N., de Veer, A.J.E., Hertogh, C.M.P.M., Francke, A.L., 2013. Respecting autonomy in the end-of-life care of people with intellectual disabilities: a qualitative multiplecase study. Journal of Intellectual Disability Research. http://dx.doi.org/10.1111/jir.12023.

Botsford, A.L., 2004. Status of end of life care in organizations providing services for older people with a developmental disability. American Journal on Mental Retardation 109 (5), 421-428.

CBS (Statistics Netherlands), 2012. Verpleegkundigen aan het werk. Sociaaleconomische trends, 1e kwartaal 2012. Statistisch kwartaalblad over arbeidsmarkt, sociale zekerheid en inkomen (Nurses at work. Socioeconomic trends, 1st quarter 2012. Quarterly statistics on employment, social security and income). CBS, Den-Haag.

De Veer, A.J., Francke, A.L., 2010. Attitudes of nursing staff towards electronic patient records: a questionnaire survey. International Journal of Nursing Studies 47 (7), 846-854. 
Bekkema, N., Veer, A.J.E. de, Albers, G., Hertogh, C.M.P.M., Onwuteaka-Philipsen, B.D., Francke, A.L. Training needs of nurses and social workers in the end-of-life care for people with intellectual disabilities: a national survey. Nursing Education Today: 2014, 34(4), 494-500

De Veer, A.J.E., Francke, A.L., Speet, M., Poortvliet, E.P., 2004. Verpleegkundige zorg rondom het overlijden van mensen met een verstandelijke beperking: een verkenning van ervaringen en meningen van verpleegkundigen (Nursing care at the end of life of people with intellectual disabilities: an exploration of experiences and opinions of nurses). NTZ 2, 110-122.

De Veer, A.J., Fleuren, M.A., Bekkema, N., Francke, A.L., 2011. Successful implementation of new technologies in nursing care: a questionnaire survey of nurse-users. BMC Medical Informatics and Decision Making 11, 67.

De Vlieger, M., Gorchs, N., Larkin, P.J., Porchet, F., 2004. A guide for the development of palliative nurse education in Europe. Palliative Nurse Education: Report of the EAPC Task Force.EAPC Onlus, Milan.

Ellison, N.M., Rosielle, D., 2008. Palliative care for adults with developmental disabilities. Journal of Palliative Medicine 11 (9), 1262-1263.

Escobar Pinzón, L.C., Claus, M., Zepf, K.I., Letzel, S., Fischbeck, S.,Weber, M., 2011. Preference for place of death in Germany. Journal of Palliative Medicine 14 (10), 10971103.

Friedman, S.L., Helm, D.T., Woodman, A.C., 2012. Unique and universal barriers: hospice care for aging adults with intellectual disability. American Journal on Intellectual and Developmental Disabilities 117 (6), 509-532.

Hahn, J.E., Cadogan, M.P., 2011. Development and evaluation of a staff training program on palliative care for persons with intellectual and developmental disabilities. Journal of Policy and Practice in Intellectual Disabilities 8 (1), 42-52.

Higginson, I., Sen-Gupta, G., 2000. Place of care in advanced cancer: a qualitative systematic literature review of patient preferences. Journal of Palliative Medicine 3 (3), 287-300.

Janicki, M.P., Dalton, A.J., Henderson, C.M., Davidson, P.W., 1999. Mortality and morbidity among older adults with intellectual disability: health services considerations. Disability and Rehabilitation 21 (5\&6), 284-294.

Kirkendall, A.M., Waldrop, D., Moone, R.P., 2012. Caring for people with intellectual disabilities and life-limiting illness: merging person-centered planning and patientcentered, family-focused care. Journal of Social Work in End-Of-Life and Palliative Care 8 (2), 135150.

McCallion, P., McCarron, M., Fahey-McCarthy, E., Connaire, K., 2012. Meeting the end of life needs of older adults with intellectual disabilities. In: Chang, E., Johnson, A. (Eds.), Contemporary and Innovative Practice in Palliative Care. Intech, Rijeka Croatia, pp. 255270.

McCarron, M., McCallion, P., Fahey-McCarthy, E., Connaire, K., 2010. Staff perceptions of essential pre-requisites underpinning end-of-life care for persons with intellectual disability and advanced dementia. Journal of Policy and Practice in Intellectual Disabilities 7 (2), 143-152.

McLaughlin, D., Barr, O., Mcllfatrick, S., McConkey, R., 2012. End-of-life care and people with intellectual disabilities: a multi-media educational resource. Journal of Intellectual Disability Research 56 (7\&8), 766.

$\mathrm{Ng}$, J., Li, S., 2003. A survey exploring the educational needs of care practitioners in learning disability (LD) settings in relation to death, dying and people with learning disabilities. European Journal of Cancer Care 12, 12-19.

Read, S., Cartlidge, D., 2012. Critical reflections on end-of-life care for peoplewith intellectual disabilities: a single case study approach. International Journal of Palliative Nursing 18 (1), 23-27.

Reddall, C., 2010. A palliative care resource for professional carers of people with learning disabilities. European Journal of Cancer Care 19 (4), 469-475.

Regnard, C., Reynolds, J., Watson, B., Matthews, D., Gibson, L., Clarke, C., 2007. Understanding distress in people with severe communication difficulties: developing and assessing the Disability Distress Assessment Tool (DisDAT). Journal of Intellectual Disability Research 51 (4), 277-292.

Ryan, K., McEvoy, M., Guerin, S., Dodd, P., 2010. An exploration of the experience, confidence and attitudes of staff to the provision of palliative care to people with intellectual disabilities. Palliative Medicine 24 (6), 566-572. 
Bekkema, N., Veer, A.J.E. de, Albers, G., Hertogh, C.M.P.M., Onwuteaka-Philipsen, B.D., Francke, A.L. Training needs of nurses and social workers in the end-of-life care for people with intellectual disabilities: a national survey. Nursing Education Today: 2014, 34(4), 494-500

Ryan, K., Guerin, S., Dodd, P., McEvoy, J., 2011. End-of-life care for people with intellectual disabilities: paid carer perspectives. Journal of Applied Research in Intellectual Disabilities 24, 199-207.

Schlairet, M.C., 2009. End of life care education: statewide survey of nurses' educational needs and effects of education. Journal of Professional Nursing 25 (3), 170-177.

Sheerin, F., McConkey, R., 2008. Frontline care in Irish intellectual disability services: the contribution of nurses and non-nurse care staff. Journal of Intellectual Disabilities 12 (2), 127-141.

Stein, G.L., 2008. Providing palliative care to people with intellectual disabilities: services, staff knowledge, and challenges. Journal of Palliative Medicine 11 (9), 1241-1248.

Sweeney, J., Mitchell, D., 2009. A challenge to nursing: an historical review of intellectual disability nursing in the UK and Ireland. Journal of Clinical Nursing 18 (19), 2754-2763.

Symons, F.J., Shinde, S.K., Gilles, E., 2008. Perspectives on pain and intellectual disability. Journal of Intellectual Disability Research 52 (4), 275-286.

Tuffrey-Wijne, I., 2012. A new model for breaking bad news to people with intellectual disabilities. Palliative Medicine 27 (1), 5-12.

Tuffrey-Wijne, I., Hogg, J., Curfs, L.M.G., 2007. End-of-life and palliative care for people with intellectual disabilities who have cancer or other life-limiting illness: a review of the literature and available resources. Journal of Applied Research in Intellectual Disabilities 20 (4), 331-344.

Tuffrey-Wijne, I., Whelton, R., Curfs, L., Hollins, S., 2008. Palliative care provision for people with intellectual disabilities: a questionnaire survey of specialist palliative care professionals in London. Palliative Medicine 22 (3), 281-290.

Tuffrey-Wijne, I., Bernal, J., Hollins, S., 2010. Disclosure and understanding of cancer diagnosis and prognosis for people with intellectual disabilities: findings from an ethnographic study. European Journal of Oncology Nursing 14, 224-230.

van der Windt, W., Smeets, R., Arnold, E., 2009. Regiomarge 2009. De arbeidsmarkt van verpleegkundigen, verzorgenden en sociaalagogen 2009-2013 (The employment of nurses, nursing assistants and social workers in 2009-2013). Prismant, Utrecht.

Whittaker, E., Kernohan, W., Hasson, F., Howard, V., McLaughlin, D., 2006. The palliative care education needs of nursing home staff. Nurse Education Today 26, 501-510.

WHO, 2012. http://www. who.int/cancer/palliative/definition/en/ (accessed 14/12/2012).

Wiese,M., Stancliffe, R.J., Balandin, S., Howarth, G., Dew, A., 2012a. End-of-life care and dying: issues raised by staff supporting older people with intellectual disability in community living services. Journal of Applied Research in Intellectual Disabilities. http://dx.doi.org/10.1111/jar.12000.

Wiese, M., Dew, A., Stancliffe, R.J., Howarth, G., Balandin, S., 2012b. 'If and when?': the beliefs and experiences of community living staff in supporting older people with intellectual disability to know about dying. Journal of Intellectual Disability Research. http://dx.doi.org/10.1111/j.1365-2788.2012.01593.x. 
Bekkema, N., Veer, A.J.E. de, Albers, G., Hertogh, C.M.P.M., Onwuteaka-Philipsen, B.D., Francke, A.L. Training needs of nurses and social workers in the end-of-life care for people with intellectual disabilities: a national survey. Nursing Education Today: 2014, 34(4), 494-500

TABLES

Table 1

Background of the respondents, by profession.

\begin{tabular}{|c|c|c|c|}
\hline & $\begin{array}{l}\text { Total } \\
\text { (weighted) }\end{array}$ & $\begin{array}{l}\text { Nursing } \\
\text { staff } \\
(\mathrm{n}=93)\end{array}$ & $\begin{array}{l}\text { Social } \\
\text { workers } \\
(n=37)\end{array}$ \\
\hline Type of professionals (\%) & & 71.5 & 28.5 \\
\hline Age (mean) ${ }^{a}$ & 44.0 & 47.3 & 42.7 \\
\hline Work experience in years (mean) ${ }^{\mathrm{b}}$ & 17.4 & 22.2 & 15.2 \\
\hline $\begin{array}{l}\text { Recent experience in end-of-life care: } \\
\text { cared for terminally ill clients during } \\
\text { the last two years (\%) }\end{array}$ & 21.0 & 37.6 & 13.9 \\
\hline $\begin{array}{l}\text { Works in a team or department specialized } \\
\text { in end-of-life care (\%) }\end{array}$ & 4.3 & 6.0 & 2.9 \\
\hline $\begin{array}{l}\text { lifferences } \mathrm{p}<.05: \\
{ }^{\mathrm{a}} \mathrm{t}=2.6657, \mathrm{p}=0.009 \\
\mathrm{~b} \mathrm{t}=4.2247, \mathrm{p}=0.000 \\
{ }^{\mathrm{c}} \text { Chi-square }=6.8405, \mathrm{p}=0.009\end{array}$ & & & \\
\hline
\end{tabular}

Table 2

Appraisal of the quality of end-of-life care by own team/department.

\begin{tabular}{llll}
\hline Evaluation ( $\mathrm{n}=92)$ & Total (weighted) & $\begin{array}{l}\text { Nursing staff } \\
(\mathrm{n}=67)^{\mathrm{a}}\end{array}$ & $\begin{array}{l}\text { Social workers } \\
(\mathrm{n}=25)^{\mathrm{a}}\end{array}$ \\
\hline $\begin{array}{l}\text { (Very) good (\%) } \\
\text { Moderately good (\%) }\end{array}$ & 79.7 & 79.1 & 80.0 \\
(Moderately) bad (\%) & 0.9 & 17.9 & 20.0 \\
$\begin{array}{l}\text { Evaluation score for quality } \\
\text { of end-of-life care (mean, }\end{array}$ & 3.86 & 3.0 & 0.0 \\
$\quad$ range 1-5, 5 = very good) & & 3.99 & 3.80 \\
\hline
\end{tabular}

${ }^{a}$ Only respondents whose team/department provided end-of-life care answered this question. 
Bekkema, N., Veer, A.J.E. de, Albers, G., Hertogh, C.M.P.M., Onwuteaka-Philipsen, B.D., Francke, A.L. Training needs of nurses and social workers in the end-of-life care for people with intellectual disabilities: a national survey. Nursing Education Today: 2014, 34(4), 494-500

Table 3

Past vocational training (basic and post basic) in end-of-life care received by nurses and social workers.

\begin{tabular}{|c|c|c|c|}
\hline & $\begin{array}{l}\text { Total (weighted) } \\
\%\end{array}$ & $\begin{array}{l}\text { Nursing staff } \\
\%\end{array}$ & $\begin{array}{l}\text { Social workers } \\
\%\end{array}$ \\
\hline \multicolumn{4}{|l|}{ Perception of end-of-life care training } \\
\hline Feels adequately trained to provide good end-of-life care & 15.4 & $27.5(n=80)$ & $10.0(\mathrm{n}=30)$ \\
\hline Took separate module on end-of-life care & 5.9 & $13.1(\mathrm{n}=84)$ & $2.9(n=34)$ \\
\hline \multicolumn{4}{|l|}{ End-of-life care topics covered in vocational training (basic and/or post basic) } \\
\hline Received at least one end-of-life care topic & 77.8 & $82.8(n=93)$ & $75.7(\mathrm{n}=37)$ \\
\hline \multicolumn{4}{|l|}{ Physical and medical care } \\
\hline Physical care of deceased client ${ }^{\mathrm{a}}$ & 20.6 & 50.5 & 8.1 \\
\hline End-of-life decisions (e.g., starting or foregoing treatment) & 14.6 & 17.2 & 13.5 \\
\hline Palliative sedation & 7.6 & 12.9 & 5.4 \\
\hline Law and regulations on euthanasia and assisted suicide & 7.3 & 11.8 & 5.4 \\
\hline Use of instruments to measure pain and other symptoms & 2.5 & 8.6 & - \\
\hline \multicolumn{4}{|l|}{ Psychosocial and spiritual care } \\
\hline Support in dealing with the impending death ${ }^{b}$ & 36.8 & 53.8 & 29.7 \\
\hline Conducting 'bad-news' conversation & 42.2 & 39.8 & 43.2 \\
\hline Religious and spiritual support & 21.9 & 16.1 & 24.3 \\
\hline Talking about the meaning of life & 19.1 & 12.9 & 21.6 \\
\hline \multicolumn{4}{|l|}{ Practical and complementary care } \\
\hline Practical issues surrounding the dying process and the funeral (e.g, clothing of the client) ${ }^{c}$ & 25.7 & 41.9 & 18.9 \\
\hline Complementary care (e.g, massage) & 6.0 & 14.0 & 2.7 \\
\hline Knowledge about end-of-life care in other cultures & 9.9 & 7.5 & 10.8 \\
\hline \multicolumn{4}{|l|}{ Personal and team development } \\
\hline Cooperation with other professions in end-of-life care ${ }^{d}$ & 18.4 & 36.6 & 10.8 \\
\hline Dealing with own grief & 28.6 & 25.8 & 29.7 \\
\hline Reflecting on own ideas and thoughts on end-of-life care & 22.9 & 25.8 & 21.6 \\
\hline
\end{tabular}

Odds ratios (OR) are corrected for the influence of recent experience in end-of-life care $(0=$ nurses, $1=$ social workers) $\mathrm{p}<.05$ :

a OR: 0.104 [0.029-0.368], p $=0.000$.

b OR: 0.353 [0.150-0.829], $\mathrm{p}=0.017$.

c OR: 0.379 [0.148-0.971], $\mathrm{p}=0.043$.

d OR: 0.183 [0.051-0.654], p = 0.009.

Table 4

Needs for additional training among nurses and social workers.

\begin{tabular}{|c|c|c|c|}
\hline & $\begin{array}{l}\text { Total (weighted) } \\
\%\end{array}$ & $\begin{array}{l}\text { Nursing staff } \\
(\mathrm{n}=86)(\%)\end{array}$ & $\begin{array}{l}\text { Social workers } \\
(\mathrm{n}=36)(\%)\end{array}$ \\
\hline Has end-of-life care training need(s) & 67.9 & 70.9 & 66.7 \\
\hline \multicolumn{4}{|l|}{ Topics in which training is needed } \\
\hline Law and regulations on euthanasia and assisted suicide & 35.4 & 33.7 & 36.1 \\
\hline Palliative sedation & 25.8 & 27.9 & 25.0 \\
\hline End-of-life decisions (e.g., starting or foregoing treatment) & 24.5 & 23.3 & 25.0 \\
\hline Technical instrumental care (e.g., catheter or ostomy care, wound care) & 9.9 & 20.9 & 5.6 \\
\hline Conducting conversations on physical condition and care needs & 17.2 & 11.6 & 19.4 \\
\hline Basic physical care (e.g., washing, feeding, clothing) & 13.3 & 4.7 & 16.7 \\
\hline Physical care of deceased client & 7.3 & 4.6 & 8.3 \\
\hline \multicolumn{4}{|l|}{ Psychosocial and spiritual care } \\
\hline Support in dealing with the impending death and the farewell process & 43.7 & 34.9 & 47.2 \\
\hline Conducting meaning of life conversations & 22.9 & 17.4 & 25.0 \\
\hline Conducting 'bad-news' conversations & 22.2 & 15.1 & 25.0 \\
\hline Religious and spiritual support & 15.6 & 5.8 & 19.4 \\
\hline \multicolumn{4}{|l|}{ Practical and complementary care } \\
\hline Knowledge about end-of-life care in other cultures & 39.4 & 33.7 & 41.7 \\
\hline Complementary care (e.g, massage) & 15.6 & 19.8 & 13.9 \\
\hline Practical issues surrounding the dying process and the funeral (e.g, clothing of the client) & 9.0 & 3.5 & 11.1 \\
\hline Home care (e.g., cleaning making dinner) & 0.7 & 2.3 & - \\
\hline \multicolumn{4}{|l|}{ (Inter)personal development } \\
\hline Dealing with own grief & 21.9 & 14.0 & 25.0 \\
\hline
\end{tabular}

No differences were found between the professions (correcting for the influence of recent experience in end-of-life care). 